\title{
Staphylococcus saprophyticus as a urinary pathogen: a six year prospective survey
}

\author{
LINDA PEAD, ROSALIND MASKELL, JULIE MORRIS
}

\begin{abstract}
Over six years (1978-83, inclusive) weekly laboratory records of organisms causing urinary tract infection in women aged 15-25 not attending hospital were kept prospectively and analysed. The incidence of infection with Staphylococcus saprophyticus defined by age and sex was confirmed. This organism caused an increasing proportion of infections in young women over the six years studied, and these infections showed noticeable seasonality. All but four isolates of $S$ saprophyticus were sensitive to all the commonly used antimicrobial agents that were tested. This might be because the organism is not often present in the body as a commensal and therefore not subject to the selection pressures exerted by such agents.
\end{abstract}

As infection with $S$ saprophyticus has different clinical connotations from infection with other coagulase negative staphylococci it should be differentiated from them in routine laboratory practice.

\section{Introduction}

Although published reports on the role of Staphylococcus saprophyticus (formerly known as Micrococcus subgroup 3) as a urinary pathogen date back to Pereira, ${ }^{1}$ Mabeck, ${ }^{2}$ and Mitchell, ${ }^{3}$ general recognition that it is a true pathogen has been slow. ${ }^{4}$ In 1974 we noted the high incidence of pyuria accompanying these infections and that the incidence was well defined by age and sex, most infections occurring in women between the ages of

\footnotetext{
Public Health Laboratory, St Mary's Hospital, Portsmouth PO3 6AQ

LINDA PEAD, AIMLS, research assistant

ROSALIND MASKELL, DM, MRCP, senior medical microbiologist

Medical Research Council Environmental Epidemiology Unit, University of Southampton, Southampton SO9 5NH

JULIE MORRIS, MSC, statistician

Correspondence and requests for reprints to: Dr Maskell.
}

15 and 25 not attending hospital. ${ }^{5}$ Having confirmed our preliminary observations on this organism and the reliability of resistance to novobiocin as a diagnostic test in more detailed studies using the Baird-Parker typing system, ${ }^{6}$ we incorporated a novobiocin disc into our first line sensitivity tests. Thus we have been able to detect the organism reliably and without added workload.

Since 1978 we have kept weekly records of all infections with $S$ saprophyticus, relating them to the total number of specimens of urine received and infections with other organisms in the principal age group affected.

\section{Subjects and methods}

Records for the six years 1978-83, inclusive, were analysed. Women between the ages of 15 and 25, inclusive, not attending hospital (excluding hospital outpatients as well as inpatients) were designated as the study group. The number of urine specimens received from all other sources and the number received from the study group were recorded. The number of specimens from the study group that were infected was recorded and the distribution of the organisms analysed.

The term coliform was used to include all Gram negative bacilli other than Proteus spp and Pseudomonas spp. All isolations of $S$ saprophyticus from patients who were not in the study group (comparison group) were also recorded and the distribution analysed. Records were kept of the antibacterial sensitivities of all isolates of $S$ saprophyticus and the presence or absence of pyuria (defined as 10 or more leucocytes $/ \mathrm{mm}^{3}$ of uncentrifuged urine).

Throughout the study the primary isolation medium for culturing midstream urine samples was cysteine lactose electrolyte deficient agar, and our criterion for interpreting significance (a count of at least $10^{7}$ colony forming units/l) did not change. Sensitivity testing was by a modified Stokes' method.?

\section{Results}

The total number of urine specimens received increased steadily from 39450 in 1978 to 61305 in 1983 . In 1978 and $1983,3909(10 \%)$ and $6234(10 \%)$ specimens, respectively, were from women in the study group; there were, however, small variations in this percentage over the six years, and a linear trend test ${ }^{8}$ showed evidence of a significant increase during this period $\left(\chi^{2}=20 \cdot 3,1 \mathrm{df}, \mathrm{p}<0.01\right)$. In 1978 and 1983 there were $931(24 \%)$ and $1516(24 \%)$ infected midstream urine samples from women in the study group; there were small variations in the intervening years but no significant overall trend.

Table I shows the distribution of the four main groups of organisms 
TABLE I-Distributions of the four main groups of organisms isolated from study group

\begin{tabular}{lccccc}
\hline & \multirow{2}{*}{$\begin{array}{c}\text { Total No of } \\
\text { infected midstream } \\
\text { Year }\end{array}$} & \multicolumn{4}{c}{ No (\%) of midstream urine samples infected with: } \\
\cline { 3 - 6 } & urine samples & Coliforms & S saprophyticus & Proteus spp & $\begin{array}{c}\text { Streptococcus } \\
\text { faecalis }\end{array}$ \\
\hline 1978 & 931 & $674(72)$ & $159(17)$ & $51(5)$ & $24(3)$ \\
1979 & 1041 & $794(76)$ & $140(13)$ & $59(6)$ & $28(3)$ \\
1980 & 1087 & $781(72)$ & $178(16)$ & $59(5)$ & $40(4)$ \\
1981 & 1277 & $917(72)$ & $230(18)$ & $65(5)$ & $26(2)$ \\
1982 & 1282 & $915(71)$ & $261(20)$ & $56(4)$ & $28(2)$ \\
1983 & 1516 & $1103(73)$ & $269(18)$ & $91(6)$ & $33(2)$ \\
\hline
\end{tabular}

TABLE II-Number of $S$ saprophyticus infections

\begin{tabular}{|c|c|c|c|}
\hline Year & Study group & $\begin{array}{c}\text { Women aged } \\
26-50 \text { not } \\
\text { attending hospital }\end{array}$ & Others \\
\hline $\begin{array}{l}1978 \\
1979 \\
1980 \\
1981 \\
1982 \\
1983\end{array}$ & $\begin{array}{l}159 \\
140 \\
178 \\
230 \\
261 \\
269\end{array}$ & $\begin{array}{r}67 \\
89 \\
72 \\
105 \\
117 \\
102\end{array}$ & $\begin{array}{l}37 \\
39 \\
31 \\
38 \\
45 \\
44\end{array}$ \\
\hline
\end{tabular}

Statistical tests for seasonality ${ }^{\circ 10}$ were performed using monthly figures summed over the six years as seasonal effects appeared comparable from year to year. Assuming that a simple harmonic cyclic trend over 12 months is followed, the peak compares to the maximum point on a fitted sine curve and the trough to the minimum point.

The summed monthly figures for both the total number of urine specimens received and the number from the study group showed significant seasonal patterns $\left(\chi^{2}=613,2 \mathrm{df}, \mathrm{p}<0.01\right.$, and $\chi^{2}=257$, $2 \mathrm{df}, \mathrm{p}<0.01$, respectively), each with a peak in early October.

The figure shows the monthly proportions of infections with different organisms to the number of infected midstream urine samples from the study group. There was a significant seasonal pattern for $S$ saprophyticus infections $\left(\chi^{2}=44 \cdot 7,2 \mathrm{df}, \mathrm{p}<0.01\right)$, the peak occurring in the middle of September, and a significant seasonal pattern for coliform infections $\left(\chi^{2}=7.5,2 \mathrm{df}, \mathrm{p}<0.05\right)$, the peak occurring in the middle of March. Proteus infections showed no significant seasonal pattern.

Infections with $S$ saprophyticus in relation to all midstream urine samples received from the study group also showed a significant seasonal pattern $\left(\chi^{2}=67.5,2 \mathrm{df}, \mathrm{p}<0.01\right)$, the peak occurring in early September. Likewise, in the comparison group the number of $S$ saprophyticus infections in relation to the number of specimens received showed a significant seasonal pattern $\left(\chi^{2}=72 \cdot 6,2 \mathrm{df}, \mathrm{p}<0.01\right)$, this peak occurring in early October.

TABLE III-Distribution of $S$ saprophyticus in comparison group. Values are numbers of isolates

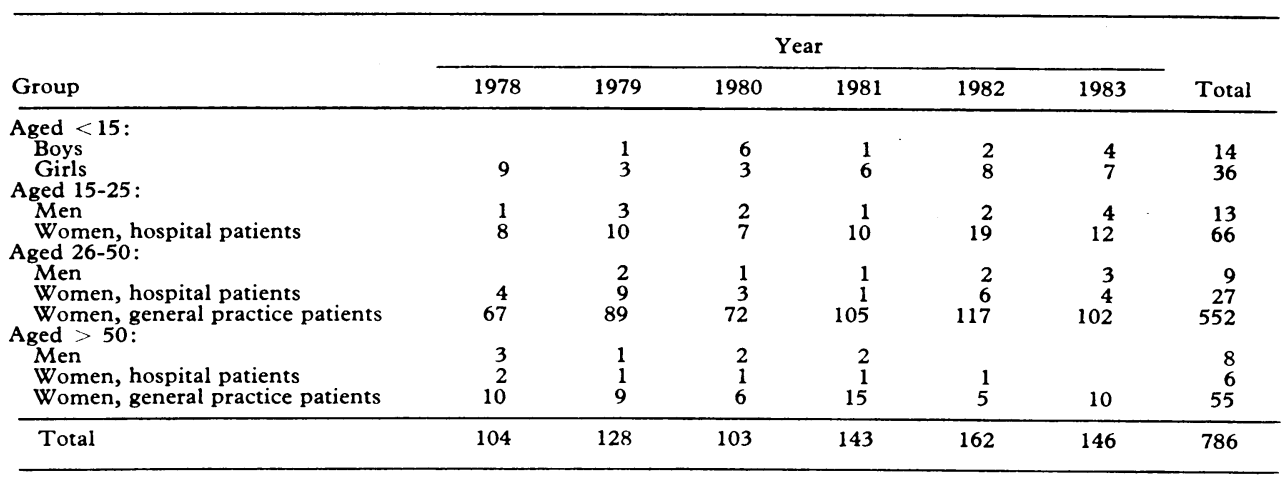

isolated from midstream urine samples from the study group during the six years. In addition to the four main groups of organisms, there were 82 isolates of Staphylococcus epidermidis, 43 group B haemolytic streptococci, 17 Staphylococcus aureus, and 10 Pseudomonas spp. These organisms accounted for less than $4 \%$ of the total number of infections. With the exception of the year 1979, when infections with $S$ saprophyticus fell to $13 \%$, this organism accounted for between $16 \%$ and $20 \%$ of all infections in the study group. The decrease in 1979 was significant $(p<0.05)$, but a linear trend test showed an increase over the six years $\left(x^{2}=7 \cdot 6,1 \mathrm{df}, \mathrm{p}<0.01\right)$. This increase did not correspond to a significant steady decrease in the proportion of any one particular group of organisms over the same period.

Table II shows the yearly numbers of infections with $S$ saprophyticus in women in the study group and in the comparison group. The proportion of $S$ saprophyticus infections to the number of midstream urine samples received from the study group showed a significant linear trend upwards: $\left(\chi^{2}=6.8,1 \mathrm{df}, \mathrm{p}<0.01\right)$. In the comparison group the proportion of $S$ saprophyticus infections to the total number of specimens received did not differ significantly over the six years.

Table III shows the distribution of $S$ saprophyticus infections in the comparison group. There were no significant changes in the distribution of infections, the greatest number occurring every year in women between the ages of 26 and 50 not attending hospital. A small number of infections occurred in men each year; these were distributed over all the age groups, including children, and showed no significant differences over the period studied.

Pyuria was associated with 1902 of 2023 S saprophyticus infections. All except four of 2023 isolates were sensitive in vitro to all agents tested; nitrofurantoin, sulphonamide, amoxycillin, and co-trimoxazole. Four strains, isolated after 1979 when trimethoprim alone became available for clinical use, were sensitive to sulphonamide but resistant to trimethoprim and co-trimoxazole. $S$ saprophyticus was isolated repeatedly from the urine of two patients who had renal stones.

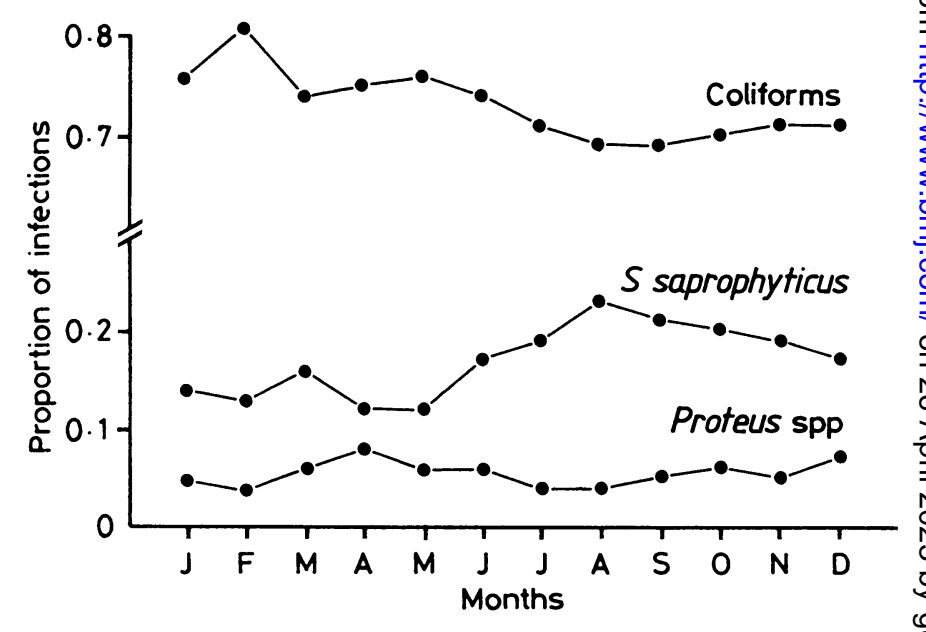

Monthly proportions of infections in women in the study group due to each group of organisms.

\section{Discussion}

Our methods for diagnosing significant urinary tract infections with aerubic pathogens did not change over the six year study period, and therefore our results from 1983 are comparable to those from 1978. Although there was an increase in the number of midstream urine samples received from the study group during 
the six years, there was no significant increase in the proportion that were infected.

Each year $S$ saprophyticus was the second commonest pathogen isolated from the study group, and the proportion of infections with this organism increased. In all except one year it accounted for at least $16 \%$ of infections. Possible reasons for its absence, or much lower percentage, in results from many other laboratories are the use of inappropriate culture media, unwillingness to accept coagulase negative staphylococci as pathogens, studies undertaken on a wider age group, and studies undertaken at times of the year when the incidence of $S$ saprophyticus infection is at its lowest.

We confirmed the results of several previous reports that most of these infections occur in young women not attending hospital, the second largest incidence being in women aged 26-50, also not attending hospital. ${ }^{5611-13}$ These infections rarely occur in patients in hospital; in our experience isolates of $S$ saprophyticus from hospital inpatients are invariably from those, including some young boys, admitted as emergencies because of the very severe symptoms caused by infection with this organism. We have never encountered a hospital acquired infection.

The high incidence of pyuria ( $94 \%$ ) suggests that $S$ saprophyticus, despite its inappropriate name, is an acute pathogen causing a severe inflammatory response; we have never knowingly isolated it from a symptom free patient (in contrast with experience with Escherichia coli or Proteus spp), and it seldom features in screening studies of asymptomatic women.

One of us (RM) has followed patients with recurrent urinary tract infections in a urinary infection clinic over the past 16 years; the only radiological abnormalities found in association with this organism were renal stones in two patients. $S$ saprophyticus was isolated repeatedly over several years from both patients, suggesting that the calculi were "infection stones" caused by the presence of organisms that split urea in the renal pelvis.

Hovelius et al showed evidence of renal disorder during attacks of infection with $S$ saprophyticus (renal tenderness and evidence of reduced concentrating capacity) and reported three patients with renal calculi; from one the organism was isolated from urine collected from the renal pelvis. ${ }^{14}$ Fowler also reported the isolation of this organism from a renal stone. ${ }^{15} S$ saprophyticus may, therefore, reach the renal pelvis, accounting for the severe symptoms, but is not associated with renal scarring. This may be because the renal scarring process begins in childhood when infections with this organism are rare. We have not isolated $S$ saprophyticus from children of either sex under 5 years of age.

In contrast with all other urinary pathogens, a proportion of which have become resistant to many commonly used antibiotics, our isolates of $S$ saprophyticus remained sensitive to all the agents tested throughout the six year period, the only resistant isolates being four strains that were resistant to trimethoprim. (We were unable to compare our results with those from other reports because all the large published reports include $S$ saprophyticus with other coagulase negative staphylococci or with "micrococci," which have developed resistance to many antibacterial agents.) As $S$ saprophyticus has remained sensitive to many antibiotics it may not, unlike other pathogens of the urinary tract and other staphylococci, be present normally in the body as a commensal and therefore not subject to the selection pressure exerted on commensals by antibiotics.

Sellin et al looked for the organism in the urethral flora of young women but found it rarely. ${ }^{16}$ Hovelius et al reported isolations from specimens from indwelling catheters from men ${ }^{17}$ and urethral swabs from men attending a venereal disease clinic. ${ }^{18}$ Perhaps the reservoir of infection is in the male, not female, urethra, and the continuing sensitivity might be due to young men receiving much less antibacterial treatment than young women who are prone to cystitis.

Although $S$ saprophyticus infections occur throughout the year, the large number of specimens studied in this series enables us to confirm conclusively that they have a noticeable seasonal incidence, both in the study group and in other age and sex groups. In contrast with coliform infections, which show a significant peak in March, $S$ saprophyticus infections occur most often in late summer and early autumn. In this laboratory we serve an area that is a holiday resort and has a large population of students. Thus the number of young women presenting with urinary tract infections will probably rise during the summer and early autumn. This would account for the significant increase in the number of midstream urine samples received from the study group at this time. It does not, however, explain the significant increase in the proportion of infections due to $S$ saprophyticus. This organism may be present more often as a commensal during late summer and early autumn; or $S$ saprophyticus infection may occur early in a woman's sexual life (holiday encounters or students arriving at college). Why then should infections occur in quite a large number of women over 25 years ? Only longitudinal studies of individual patients, their commensal flora, and that of their sexual partners will answer this question. Such studies, in the age group affected, are notoriously difficult to carry out.

The mode of pathogenicity of an organism with such a circumscribed incidence could be relevant. O'Garra et al showed that some strains can adhere to human epithelial cells whereas others cannot, and electron microscopy showed that both the adherent strains and the epithelial cells had a surface coat composed of a type of acidic polysaccharide. ${ }^{19}$ Pead found that non-specific agglutination occurred between heated suspensions of $S$ saprophyticus and IgM fractions of human sera but was not detectable when the suspensions contained a high proportion of cocci bearing an electron lucid halo. ${ }^{20}$ Recently, Gunnarsson et al reported the presence of oligosaccharide structures mediating agglutination of sheep erythrocytes by $S$ saprophyticus. ${ }^{21}$

Many problems relating to infection with this organism remain. It is now clear, however, that it has different clinical connotations from infection with other species of coagulase negative staphylococci and should be differentiated from them in routine laboratory practice.

We thank Professor D J P Barker for advice and Mrs Terry Diplock for typing the manuscript.

\section{References}

1 Pereira AT. Coagulase-negative strains of staphylococcus possessing antigen 51 as agents of urinary infection. $\mathcal{F}$ Clin Pathol $1962 ; 15: 252-3$

Mabeck CE. Significance of coagulase-negative staphylococcal bacteriuria. Lance 1969;ii:1150-2

3 Mitchell RG. Classification of Staphylococcus albus strains isolated from the urinary tract. $\mathcal{F}$ Clin Pathol 1968;21:93-6.

4 Komaroff AL. Acute dysuria in women. N Engl 7 Med 1984;310:368-75. Maskell R. Importance of coaguiase-negative staphylococci as pathogens in the

Pead L, Crump J, Maskell R. Staphylococci as urinary pathogens. 7 Clin Pathol Pearson CM, Whiteh

method using a method using a rotary plater. 7 Clin Pathol 1974;27:430-1.

Publicat. Statistical methods in medical research. Oxford: Blackwell Scientific

Edwards JH. The recognition and estimation of cyclic trends. Ann Hum Gen $1961 ; 25: 83-7$.

Walter SD, Elwood JM. A test for seasonality of events with a variable population at risk. British fournal of Preventive and Social Medicine 1975;29:18-2

12 Jordan PA, Irvani A, Richard GA. Urinary tract infection caused by Staphylococcus saprophyticus. F Infect Dis 1980;142:510-5.

13 Marrie TJ, Kwan C, Noble MA, West A, Duffield L. Staphylococcus saprophyticus as a cause of urinary tract infections. $\mathcal{f}$ Clin Microbiol 1982;16:427-31. 4 Hovelius B, Mảrdh P-A, Bygren P. Urinary tract infections caused by Staphylococcus saprophyticus: recurrences and complications. $\mathcal{F}$ Urol 1979;122:645-7.

15 Fowler JE. Staphylococcus saprophyticus as the cause of infected urinary calculus. Ann Intern Med 1985;102:342-3.

Sellin MA, Cooke DI, Gillespie WA, Sylvester DGH, Anderson JD. Micrococcal urinary-tract infections in young women. Lancet 1975 ;ii:570-2.

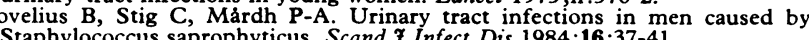
Staphylococcus saprophyticus. Scand Infect Dis $1984 ; 16: 37-41$.
Hovelius B, Thelin I, Márdh P-A. Staphylococcus saprophyticus in the aetiology of non-gonococcal urethritis. Br $\mathcal{Y}$ Vener Dis 1979;55:369-74.

19 O'Garra A, Ward JB, Burdett IDJ. Studies on the adhesion of Staphylococcus saprophyticus to human epithelial cells. Annual Review of the American Society of Microbiology 1983;55. (Abstract No B189.)

20 Pead PJ. Investigation of humoral antibody response by agglutination test in urinary tract infection associated with Staphylococcus saprophyticus. Guildford: University of Surrey, 1981. (MSc thesis.)

21 Gunnarsson A, Márdh P-A, Lundblad A, Svensson S. Oligosaccharide structures mediating agglutination of sheep erythrocytes by Staphylococcus saprophyticus.

Accepted 22 fuly 1985) 